\title{
Subjective/ Behavioural Factors Influence the PSI 20 and IBEX 35
}

\author{
Stefan Abrantes Costa ${ }^{1}$, Pedro Manuel Nogueira Reis ${ }^{1} \&$ António Pedro Soares Pinto ${ }^{1}$ \\ ${ }^{1}$ Polytechnic Institute of Viseu, Portugal \\ Correspondence: António Pedro Soares Pinto, Associate Professor, Polytechnic Institute of Viseu, Portugal. E-mail: \\ spinto@estv.ipv.pt
}

Received: July 28, 2020

doi:10.5430/ijfr.v11n5p13

Accepted: September 5, 2020

Online Published: September 21, 2020

URL: https://doi.org/10.5430/ijfr.v11n5p13

\begin{abstract}
This study assesses the impact of investor sentiment on the volatility of the PSI 20 and IBEX 35 from time series data from January 1988 to May 2019. The impact of investor sentiment on market and portfolio selection has aroused great interest in the literature, however the results obtained are not consensual, considering the different methodologies used to build sentiment indices, as well as the various levels of institutional development in the market.

Asymmetric volatility behaviours according to good or bad news were evaluated using the TGARCH model. The results indicate that there is an asymmetric effect of good versus bad news on the volatility of IBEX 35. It was also noted that for Portugal and Spain investor sentiment presents statistical significance with a negative sign, suggesting that market volatility is more sensitive to negative shocks in the conditional variance. In Portugal, contrary to Spain, sentiment has no relevance on return. The study reveals that investor sentiment is a key factor in selecting investment in the market. The relationship that this establishes with volatility, can help to implement policies that allow to minimize future shocks' impact on return. The study reveals for the first time that investor sentiment is a key factor in selecting investment in the market for Portugal.
\end{abstract}

Keywords: investor sentiment, volatility, stock market

\section{Introduction}

The study of financial markets has been gaining importance over time, and the behaviour and influence of investors on the global financial market has become particularly important in recent years, as a better understanding of how it works and how stakeholders interact can help improve profitability. To this end, a number of studies have been developed to assess how investor sentiment influences the market and portfolio selection (Baker \& Wurgler 2006). The increasing importance that the role of investor sentiment has assumed in behavioural finance has led its influence on the volatility of the PSI 20 to be assessed. Moreover, to the best of our knowledge, no study with this scope has yet been carried out for the Portuguese market. The consumer confidence index proposed by Charoenrook (2006), Qiu \& Welch (2006), Lemmon \& Portniaguina (2006), Schmeling (2009), Finter, Niessen-Ruenzi \& Ruenzi (2012), Chang, Faff \& Hwang (2012) and Aydogan (2016) were taken into account in undertaking this study.

Based on the methodology advocated by Aydogan (2016), we intend to analyse the impact of sentiment on volatility in the PSI 20 and to establish a comparative study with the results obtained by the author in a paper on the IBEX 35. Positive and negative news have distinct impacts on market volatility and to understand their effect on volatility the TGARCH model developed by Glosten, Jagannathan \& Runkle (1993) and Zakoian (1994) was applied.

In addition to this introductory section, the body of the work is composed of four sections. Section 2 seeks to contextualize the problem of sentiment and its impact on volatility. Section 3 covers the methodology and data collection. The estimation of the results is the subject of section 4, and section 5 presents the main conclusions.

\section{Literature Review}

The predictive power of investor sentiment in the return on shares has aroused great interest and a growing volume of literature devoted to this subject; however, the results obtained have not always engendered a consensus around this topic, bearing in mind the different methodologies used to build indices of sentiment as well as the various levels of institutional development of the market. 
Lee, Shleifer \& Thaler (1991), Han (2007) and Schneller, Heiden, Heiden \& Hamid (2017) describe the investor sentiment as the expectation of return on investments in the absence of logical grounds, expressed in the aggregate errors of their beliefs. This sentiment is associated with the irrational part of investor expectations not related with logical fundamentals, and linked with the difference between the fundamental value of an asset and the its value to an investor with irrational expectations. For Khan \& Ahmad (2018) investor sentiment stems from the conception that incorporates the way investors develop their preferences and beliefs, keeping in mind the mood, emotions, prejudice and cognitive biases and the way they subsequently predict future asset prices.

Lee, Jiang \& Indro (2002), Fisher \& Statman (2003) highlight the prevalence of a contemporary relationship between investor sentiment and the return on developed markets, especially in the US, leading Lemmon \& Portniaguina (2006) to affirm that consumer confidence plays a relevant role in the return on markets, particularly in small ones. The results corroborate the principles of behavioural finance, validating that investor sentiment influences stock returns

Baker \& Wurgler $(2006,2007)$ developed an index to measure investor sentiment based on the following proxies: closed-end discount, transaction volume measured by NYSE turnover, number of Initial Public Offerings (IPOs) and the average return on the first day of the IPOs, share participation in new issues, and the dividend premium. This indicator allowed the authors to conclude that regardless of whether sentiment at some point is high or low, US stock returns reflect practically contrasting patterns. Later, Baker, Wurgler \& Yuan (2012) develop an investor sentiment index that aggregates four proxies: volatility premium, number of IPOs, average first day returns on IPOs and trading volume in six stock markets: Germany, Canada, the United States of America, France, Great Britain and Japan.

Dergiades (2012) identifies statistical evidence that supports the idea that sentiment has significant predictive power within a framework of nonlinear causality in the American stock market. Kumar \& Lee (2006) and Sayim, Morris \& Rahman (2013) analyse the effect of investor sentiment on stock returns and US industry volatility, finding that investor sentiment has a significant positive impact on stock returns and industry volatility.

Several studies (Tsuji, 2006, Wang, Li \& Lin, 2009, Lux, 2011, Finter et al. 2012 and Yu, Huang \& Hsu, 2014) conducted in different contexts support the hypothesis that sentiment conditions share price and plays a significant influence on expected return. Existing literature has focused on developed markets, so there is little empirical evidence on the role of investor sentiment on stock profitability, particularly in emerging markets.

Corredor, Ferrer \& Santamaria (2013) assessed the effect of investor sentiment on four developed stock markets: Germany, Spain, France and Great Britain, concluding that sentiment has a significant and positive influence on return, varying in intensity from market to market. Later, Corredor, Ferrer \& Santamaria (2015) analysed the effect of sentiment on stock returns in three emerging markets in central Europe: Hungary, Poland and the Czech Republic, concluding that sentiment has a significant negative effect on stock returns, although there is a dispersion in intensity between countries.

Horta \& Lobão (2018) analysed the relationship between sentiment and market return in seven European markets (Germany, Belgium, France, Greece, the Netherlands, Portugal and the United Kingdom) and, unlike previous studies that focused on the causal relationship between the variables, they focused their analysis on the structure of dependence between investor sentiment, represented by the Economic Sentiment Indicator (ESI) proxy and market return, expressed by the Morgan Stanley Capital International (MSCI) index. Based on the copulation model, a statistical technique used to formulate multivariate distributions (Nelsen, 1999) and the bootstrap procedure (Bootstrapping is a resampling method used to approximate the sample distribution of a statistical survey proposed by Efron in 1979) to test six hypotheses, the results suggest the relevance of investor sentiment in determining market prices.

Regarding the Portuguese case, in a study analyzing the impact of sentiment on market returns in Portugal, using the return on the Portuguese stock market, Fernandes, Gonçalves \& Vieira (2013) state that the Portuguese Economic Sentiment Indicator (ESI) and the European Union (EU) Consumer Confidence Index for Portugal are driven by rational and irrational factors. The authors only used the irrational component of sentiment, concluding that sentiment has a negative impact on future market returns and may be justified by the fact that Portugal is a market prone to the influence of sentiment as a result of its high degree of collectivism, revealing the extent to which individuals are driven to act in groups rather than individually (Hofstede, 2001). The authors also conclude that there is no contagion of US investor sentiment on the Portuguese market return.

Given the relevance of investor sentiment in the behaviour of markets, the following is a brief review that helps to contextualize this issue within the framework of financial theory.

According to Baker \& Wurgler (2006), classical finance does not attach any importance to investor sentiment, arguing that competition among rational investors with diversified investments allows for efficient portfolios, which 
in turn leads to a balance where prices reflect the discounted value of expected cash flows. In the presence of irrational investors, classical theory advocates that the presence of arbitrators will be sufficient to prevent a significant deviation in prices. Thus, the impact of investor sentiment on prices becomes irrelevant as they tend to their fundamental value if markets function efficiently. According to Fama (1970), in an efficient market, prices fully reflect the available information. From the above, it appears that traditional finance does not recognize the role that investor sentiment plays in the behaviour of markets. In view of this constraint, a new current is developing within financial theory that seeks to recognize the role of this, called behavioural finance.

Between 1979 and the mid-1980s behavioural finance assumed particular relevance, seeking to address the difficulties traditional finance had in justifying the anomalies that historically characterized the market (Barberis \& Thaler 2002).

For Ritter (2003) and De Bondt, Muradoglu, Shefrin \& Staikouras (2008) behavioural finance uses models that seek to incorporate the non-rational behaviour of agents, particularly when taking into account personal preferences or less well-founded beliefs, evaluating the behaviour of investors and the way their conduct conditions the market and financial institutions (This approach takes into account the existence of "normal" investors who, unlike rational investors, are not immune to cognitive errors or false emotions and decision-making are shaped by agents' emotions, especially in periods of strong volatility (Statman, 2014; Nofsinger, 2005). Investors convey the social mood to the capital market, thereby incorporating sentiment in price formation. The capital market moves according to social mood, increasing in periods of optimism, satisfaction, confidence and decreasing in pessimistic or conservative periods (Nofsinger, 2005).

Ritter (2003) states that behavioural finance is structured on two pillars, investor cognitive psychology and the limit of arbitrage. The first refers to the way people think, and there is a significant literature documenting the errors systematically made by individuals regarding the way they think: they are overconfident, attach too much weight to recent experience, and their preferences can create distortions. Behavioural finance incorporates these principles by taking advantage of them in future situations. The second, the limit of arbitration, assesses the extent to which it becomes effective. In the presence of price imbalances, resulting from irrational decisions made by agents, arbitrators seek gains by driving prices to equilibrium.

In short, behavioural theory takes into account individual psychological aspects, considering that the conduct of some investors is conditioned by biases and emotions. Additionally, it acknowledges the prevalence of limits on arbitration, so that, under these circumstances, the price of assets may change relative to their fundamental values, so that returns may be conditioned by factors other than risk (De Long, Shleifer, Summers, \& Waldmann 1990).

Given the importance that investor sentiment plays in returns on securities, it is important to identify instruments that allow them to be quantified, namely through the volatility index. Volatility is present in financial markets and is associated with the feeling of uncertainty in the decisions that are taken daily, despite the fact that these decisions have associated risks. It is in this context that volatility is paramount, providing important information to investors, guiding decision making regarding a particular asset.

Volatility is associated with the dispersion of underlying asset prices relative to their average over a given period of time (Ferreira, 2009). This measure is usually measured by the annualized standard deviation of the percentage change in daily, weekly, monthly or very small time intervals, usually irregular intraday time scales, often referred to as high frequency data expressed as a percentage. This measure quantifies the risk of an asset traded in the financial market over a period of time by measuring the dispersion of its yields and ultimately the market itself. The higher the value of the standard deviation, the higher the volatility and the greater the uncertainty associated with the security.

Time series within financial markets have specific characteristics that seek to translate a return pattern for different assets (stocks, bonds, options, futures, other derivatives), all of which fit into at least one of the stylized facts (Taylor, 1994; Ridberg, 2000). Among the most studied "stabilized facts" in the literature are fat tails in the distribution of returns, volatility in clusters, leverage or asymmetry effect, the long memory of chronological financial successions and co-movements.

In the middle of the last century, Mandelbrot (1963) and Fama (1965) refer, by identifying homogeneous groups in describing the behaviour of chronological financial successions, the first cluster volatility. This is characterized by the fact that periods of high volatility are followed by periods of large fluctuations; similarly, that small changes in prices lead to small changes (Campbell \& MacKinlay, 1997).

The leverage effect or asymmetric effect occurs when stock prices tend to be negatively correlated with volatility changes, i.e., when volatility is higher after negative shocks rather than positive shocks of equal magnitude 
(Aydogan, 2016). There are often periods of intense volatility in financial markets after periods of price declines, which are not felt so intensely in periods when prices rise (Silva, Sáfadi \& Castro, 2005). From the foregoing, we can state that positive and negative shocks tend to have distinct impacts on volatility.

The long-term memory effects (long memory) detected for the first time in non-financial contexts are related to a high degree of persistence in observations, i.e., the volatility of financial markets is influenced by very distant shocks that reverberate over time to the present (Bollerslev \& Mikkelsen, 1996). Finally, co-movements denote synchronization of behaviours in different markets, i.e., there is a tendency towards similar behaviours. Traditionally, correlation has been used to quantify the size of joint movements and to define the degree of contagion among financial markets (Barberis, Shleifer \& Wurgler, 2005).

Following a brief description of the stylized facts of volatility, it is important to identify the main models for measuring volatility. Volatility modelling has been the subject of different studies over the years, given the difficulty in observing it directly in the market and the difficulty in describing its behaviour and reducing uncertainty. The definition of volatility is associated with asymmetric movements over a period of time without it being possible to predict its evolution. Kendall \& Hill (1953) was the first author to be interested in this topic, concluding that the movements were completely random, leading Bowerman \& O'Connell (1979) to argue that volatility represented a series of random residues over a time series, with a zero mean and uniform variance, in context characterized by the reduction of components and seasonality cycles.

Engle (1982) proposes two models to measure volatility, which symmetrically treat the effects of positive and negative returns on volatility, namely:

- Autoregressive Conditional Heteroscedasticity $(A R C H)$ : in this, the variance of a time series changes over time, conditioned to the forecast errors observed in the past;

- Generalized Autoregressive Conditional Heteroscedasticity (GARCH): further developed by Bollerslev (1986), allowing the treatment of conditioned variance to be generalized over a given period of time, depending also on the conditioned variances observed in the past and observations of the past.

Later, Glosten et al. (1993) and Zakoian (1994) developed a new variant of the GARCH model called Threshold Generalized Autoregressive Conditional Heteroscedasticity (TGARCH). Thus, it is possible to compare the impact of "good news" and "bad news", allowing us to conclude that they affect future volatility: "bad news" has a stronger negative leverage effect than "good news", revealing the clear prevalence of an asymmetric effect.

Volatility appears as an instrument for gauging market sentiment and has been the subject of much theoretical debate to identify the relationship between sentiment and volatility. For Smidt (1968) and Zweig (1973) sentiment gives rise to speculative situations in which investors try to speculate market trends based on personal intent, associated with the investors' cognitive effects.

Bentes (2011) identifies two distinct currents in the causal relationship between sentiment and volatility: one that supports a cause-and-effect relationship between sentiment and volatility used to predict future returns and the other in the opposite direction. However, literature review allows us to identify a set of studies (Solt \& Statman,1988; Brown \& Cliff, 2004; Wang, Keswani \& Taylor; 2006) in which it is difficult to reach a consensus regarding the results obtained, questioning the way sentiment is generated and witch stems from the volatility of financial markets. Furthermore, Fisher \& Statman (2000) state that the causal relationship between sentiment and volatility can be significant in both directions. The study of sentiment is relevant, so it should be studied as it persists over time, and optimism or pessimism spreads as more people share this sentiment. Added to this is the fact that arbitrage can eliminate short-term profit strategies; however, it is unable to correct long-term deviations.

Thus, it is important to measure this variable, identify and quantify market sentiment, as well as predict the future evolution of movements and trends, thereby market sentiment indices emerge, allowing us to quantify the levels of pessimism and optimism existing at every moment in the market.

The literature identifies a set of indicators that can be used to gauge sentiment, but it has been difficult to gather consensus on which one is most appropriate. Generally, sentiment indicators can be divided into direct and indirect indicators (Brown \& Cliff, 2004). Direct indicators result from surveys that seek to question individuals about their expectations and opinions about the evolution of the economy and the financial market, or through the use of consumer confidence index. Indirect indicators use economic and financial variables to check investor sentiment. Several studies (e.g., Fisher \& Statman, 2000, Brown \& Cliff, 2005, Verma \& Soydemir, 2006), use surveys to gauge 
sentiment; on the other hand, the Consumer Confidence Index (CCI), as an alternative in other studies (e.g., Charoenrook, 2006, Qiu \& Welch, 2006, Lemmon \& Portniaguina, 2006; Schmeling, 2009).

Qiu \& Welch (2006) state that the CCI is intrinsically associated with investor sentiment, as investors are optimistic about the economy when they share the same sentiment about the stock market and vice versa. This includes the rational and emotional components of consumer sentiment and the link with consumer sentiment stems from the significant presence of individual investors in the financial markets (Lemmon \& Portniaguina, 2006).

As for indirect indicators, different authors (Lee, Shleifer \& Thaler, 1991, Hughen \& McDonald, 2005) use the closed-end investment fund discount (CEFD), and the number of new initial public offerings (IPOs) is another alternative indicator (Lee et al. 1991, Wang, et al. 2006) expressed by trading volume ratio put-call.

Recently new composite indices have been proposed to measure sentiment. Glushkov (2006) developed an index consisting of the bull-bear spread (Investors Intelligence (II) from financial market journals. Every week every journal is consulted from the perspective of future market movements and is marked with bullish, bearish and neutral), dividend premium, closed-end discount, percentage change in lending margin, ratio of short sales by financial experts to total short sales, new cash flows US equity mutual funds, and the number and average of day one returns on IPOs. Baker \& Wurgler (2006), in turn, use the closed-end discount, the volume of transactions measured by the NYSE's turnover, the number and average of first day returns on IPOs, the share of new issues and dividend premiums to build a new index.

According to Fernandes, et al. (2013), it is difficult to gather a consensus on the indicators that best measure sentiment. One of the problems associated with its construction is that the sentiment indicator may only be an indicator or a proxy for macroeconomic factors already identified in the literature. (Lee et al. 1991).

Chen, Rool \& Ross (1986) and Baker \& Wurgler (2007) report that indicators may have a common component related to sentiment and macroeconomic factors. The macroeconomic variables systematically condition stock prices, identifying those that affect asset returns, suggesting others that should be removed from sentiment indicators such as annual growth in industrial production and return on the New York Stock Exchange (NYSE) weighted index. In its turn Baker \& Wurgler (2007) to remove economic factors from proxies, perform regressions for each proxy based on macroeconomic indicators, using the residuals obtained from regression as a proxy for sentiment.

Brown \& Cliff (2005) and Feldman (2010) take a different approach by incorporating control variables in regression, thus removing the influence of macroeconomic factors from the analysis, as opposed to directly excluding these factors.

The macroeconomic variables used in our study similarly to other authors are: the industrial production index (Brown \& Cliff, 2004; Baker \& Wurgler, 2007; Schmeling, 2009; Fernandes, et al. 2013; Corredor, 2015; Aydogan, 2016; Khan, 2018), short-term interest rates (Fama \& Schwert, 1977; Schmeling, 2009; Baker, Wurgel \&Yuan, 2012; Fernandes, et al. 2013; Kumari \& Mahakud 2015; Aydogan, 2016) monthly variation in the consumer price index (Zouaoui, 2011; Fernandes, et al. 2013; Sayim, Morris \& Rahmam 2013, Aydogan, 2016).

In short, investor sentiment influences market volatility, which in turn conditions the evolution of the market and its returns. There are two types of indicators for measuring investor sentiment. On the one hand, there are direct indicators obtained from surveys and the Consumer Confidence Index; and on the other hand, there are indirect indicators that use economic and financial variables to capture investor sentiment. With the help of models such as $\mathrm{ARCH}$ and GARCH, it becomes possible to model and predict market volatility movements.

\section{Data and Methodology}

The study used time series data with monthly frequency from January 1988 to May 2019 for the Portuguese and Spanish market, with two purposes: i) to assess the effect of investor sentiment on the volatility of the Portuguese stock market, the PSI 20 index and, ii) broaden its scope by comparing it with the Spanish stock market, the IBEX 35 index. The quotation of the PSI 20 and IBEX 35 index was obtained from OECD's Main Economic Indicators database (1961). In order to study the effect of investor sentiment on market volatility, a methodology similar to that proposed by Aydogan (2016), Glosten et al. (1993), and Zakoian (1994) was applied. We used the consumer confidence index as a proxy to measure investor sentiment, macroeconomic variables as control variables, and a linear regression was performed using the least squares method (Ordinary Least Squares - OLS) in order to remove the effect of the macroeconomic news in our sentiment proxy. Consumer confidence measures have been largely deployed as proxies of investor sentiment (Reis and Pinho 2020a, 2020b; He, Zhu, and Gu ,2017; Spyrou, 2013; Simões, 2011; Chui, Titman, and Wei 2010). This measure captures the consumer prospect mood and thus a lead indicator of a future behavior of the stock market return and volatility. Most findings report a negative relationship 
between sentiment and returns and a positive relation with volatility (risk). Macroeconomic variables that were considered are: the industrial production index (to measure economic growth), the monthly money market rates (namely short-term interest rates) and inflation (monthly variation in the consumer price index). The consumer confidence index and macroeconomic variables were also taken from the OECD's Main Economic Indicators database. The equation for estimating the "purified" investor sentiment is as follows:

$$
\operatorname{SENT}_{i, t}=\alpha+\beta_{j} \sum_{j=1}^{n} M A C R O_{i, t}+D_{t}+\varepsilon_{i, t}
$$

Where $S E N T_{i, t}$ represents investor sentiment for country i (Portugal or Spain) at time t- the consumer confidence index, $M A C R O_{i, t}$ expresses the following macroeconomic indicators: industrial production index, consumer price index and short-term interest rates for country $\mathrm{i}$ (Portugal or Spain) at time $\mathrm{t}, \alpha$ is the constant and $\varepsilon_{i, t}$ the error term. To analyze the impact of the global financial crisis, a dummy variable $D_{t}$ was introduced (with a value of 1 if the period is in crisis and 0 in the absence of a crisis). The global financial crisis started in July 2017 (Dungey 2009) and the end was consensually considered in December 2009 (Bhimjee, Ramos, \& Dias, 2016).

As previous requirements for obtaining the residuals of equation (1), some assumptions of the OLS estimation must be verified in time series, namely: stationarity, the absence of autocorrelation and homoscedasticity, issues addressed in a later point of this work. The residuals of expression (1) translate the original sentiment index orthogonalized by the macroeconomic variables and, thus, free of this effect. The objective of the new sentiment measure seeks to capture the pure investor sentiment, which can only be measured through a proxy. After estimating investor sentiment, we applied the Autoregressive Conditional Heteroscedasticity (ARCH) model developed by Engle (1982). The ARCH model assesses the short-term impact of shocks that occurred in the market in the previous period on current volatility. More specifically, the Generalized Autoregressive Conditional Heteroscedasticity (GARCH) model developed by Bollerslev (1986), which is widely referenced in the literature, was used to test the volatility of the markets, assessing the persistence of shocks occurred in past volatility and its impact on present volatility. This type of model allows us to capture stylized facts such as volatility clustering characterized by the fact that periods of high volatility follow periods of large fluctuations, similarly, periods with small changes in prices give rise to small fluctuations (Campbell, \& MacKinlay, 1997).

In many circumstances, it is observed that the positive and negative news from the markets have different impacts on their volatility. To understand the asymmetric behaviours of volatility according to good or bad news Glosten et al. (1993) and Zakoian (1994) developed the Threshold Generalized Autoregressive Conditional Heterocedastic (TGARCH) model. In this study, the TGARCH model has the advantage of incorporating the three arch effects (ARCH, GARCH and TGARCH) with the specificity of being composed of two equations: i) mean equation that defines the impact of sentiment on profitability and ii) the volatility equation that defines the impact of sentiment on volatility and the arch effects.

The first equation has the following algebraic expression:

$$
\begin{gathered}
Y_{t}=\alpha_{0}+\beta_{0} Y_{t-1}+\beta_{1} S E N T_{t-1}+\varepsilon_{t} \\
\frac{\varepsilon_{t}}{\Omega} \sim i . i . d .\left(0, h_{t}\right)
\end{gathered}
$$

where $Y_{t}$ represents the profitability of the shares (of the Portuguese or Spanish Index), calculated from the logarithm of the recent quotation and the quotation of the previous period of the PSI 20 or IBEX 35, depending on the cases, at time t, $S E N T_{t-1}$ represents the investor sentiment, obtained from the residuals of equation 1, calculated for the moment $\mathrm{t}-1$.

The second equation, that of volatility, is expressed as follows:

$$
h_{r, t}=\mu+\sum_{i=1}^{p} \alpha_{i} \varepsilon_{t-1}^{2}+\sum_{J=1}^{q} \beta_{j} h_{t-j}+\gamma \varepsilon_{t-1}^{2} d_{t-1}+\vartheta S E N T_{r, t-1}
$$

where $h_{r, t}$ translates the conditional variance of the stock return index (PSI20 or IBEX 35) for country r (Portugal or Spain) at time t, $S E N T_{r, t-1}$ represents the residuals estimated in expression 1, which allowed determining the sentiment for country $\mathrm{r}$ (Portugal or Spain) at time t-1. The asymmetric response to good and bad news, called the leverage effect, is being captured by the variable $d_{t}$, with $d_{t}=1$ if $\varepsilon<0$ (bad news) and 0 otherwise ( $\varepsilon>=0$ good news). Good news has an impact on $\alpha_{i}$, and bad news on $\alpha_{i}+\gamma$, meaning that bad news has a greater effect on 
volatility when $\gamma>0$, indicating the presence of the leverage effect and if $\gamma \neq 0$ news impact becomes asymmetrical. The coefficient $\alpha$ represents the ARCH effect with $\mathrm{p}=1$ (first order arch effect) and the GARCH effect is expressed by $\beta$ where $\mathrm{q}=1$ (first order arch effect). The $\vartheta$ coefficient shows the impact of the lagged effect of investor sentiment on the conditional variance of the stock profitability index, after removing the vector effect of the macroeconomic variables.

The estimation of the TGARCH model requires the following assumptions, inherent to this type of heteroscedastic modelling, to be verified in advance: the stationarity of the variables, the lack of autocorrelation of the residues, and, the hypothesis of heteroscedasticity. The stationarity assumption is verified through the widely used test, the Augmented Dickey Fuller (ADF) developed by Dickey \& Fuller (1979). The assumption of autocorrelation is verified through two tests, the Durbin Watson test developed by Durbin \& Watson (1950), and the Breusch-Godfrey LM test, developed by the authors Breusch (1978) and Godfrey (1978). Finally, in order to fulfil the assumption of heteroscedasticity, the Breusch Pagan tests proposed and developed by Breusch \& Pagan (1979) and the White test developed by White (1980) are performed.

After verifying the assumptions described and before estimating the TGARCH model, it is necessary to verify whether the time series under study includes the presence of ARCH effects, that is, to verify whether the time series has cluster volatility. For this purpose, the ARCH-LM test is performed, which was developed by the author Engle (1982), whose null hypothesis is that there are no ARCH effects.

\section{Results}

This study investigates the impact that investor sentiment has on the volatility of PSI 20 and IBEX 35, based on the methodology used by Aydogan (2016). Consumer Confidence Index data attempted to capture the effect that investor sentiment would have on conditioned volatility. In order to study the influence that sentiment has on the volatility of the Portuguese and Spanish market, it is necessary to calculate the sentiment as referred in equation 1, fulfilling the assumptions of stationarity, no autocorrelation and of absence of heteroscedasticity. To fulfil with the assumption of stationarity, the variables were transformed into their first temporary differences, and using the Augmented Dickey Fuller (ADF) test it can be verified that with this step all variables become stationary, thus achieving the assumption of stationarity.

The descriptive statistics of the variables under study are shown in the following Table 1, with the upper part of the Table representing the variables used in the Portuguese market and the lower part representing the variables used in the Spanish market. By observing the standard error value, we can see that the volatilities of the markets under study are similar, since the value of the return log in both markets does not differ significantly. The standard error values are similar to the values obtained by Aydogan (2016) for the Spanish market.

Table 1. Descriptive statistics

\begin{tabular}{rlccrcr}
\hline Country & \multicolumn{1}{c}{ Variable } & Obs & Mean & Std.Dev. & Min & Max \\
\hline \multirow{6}{*}{ Portugal } & cci & 377 & 99.90377 & 1.38275 & 96.3199 & 102.279 \\
& indprod & 377 & 112.0309 & 11.8557 & 91.5487 & 135.278 \\
& stint & 377 & 5.221057 & 5.6507 & -0.4077 & 18.254 \\
& cpi & 377 & 3.889914 & 3.78075 & -1.6648 & 14.6335 \\
& logreturn & 376 & 0.002784 & 0.04915 & -0.2209 & 0.21039 \\
& sen & 373 & $-3.08 \mathrm{E}-11$ & 0.05814 & -0.1756 & 0.18815 \\
& e & 372 & -0.00131 & 0.0445 & -0.2071 & 0.18001 \\
\hline \multirow{6}{*}{ Spain } & cci & 377 & 99.96457 & 1.27264 & 96.4808 & 101.767 \\
& indprod & 377 & 109.1365 & 12.4494 & 89.7731 & 136.636 \\
& stint & 377 & 4.821987 & 4.86261 & -0.3304 & 15.979 \\
& cpi & 377 & 3.043779 & 1.98418 & -1.3684 & 7.39318 \\
& logreturn & 376 & 0.003581 & 0.04874 & -0.1752 & 0.13704 \\
& sent & 373 & $5.07 \mathrm{E}-12$ & 0.06626 & -0.2354 & 0.24651 \\
& e & 372 & $-9.73 \mathrm{E}-04$ & 0.0462 & -0.1621 & 0.12808 \\
\hline
\end{tabular}

Note: $c c i$ is Consumer confidence index; indprod is Industrial production index, stint is Short-term interest rate; $c p i$ is the Consumer price index; logreturn is the Logarithm return of PSI 20 and IBEX 35, sent is the Consumer sentiment derived from the residuals of equation 1 and $e$ are the residuals of equation 3. 
After verifying compliance with stationarity (unit root) it was necessary to test the presence of autocorrelation using Durbin Watson (Durbin and Watson, 1950) and Breusch-Godfrey LM (Breusch, 1978 and Godfrey, 1978) tests, so that the assumption is fulfilled it is necessary that there is no autocorrelation.

To correct the problem of pre-existing autocorrelation, an autoregressive AR (p) model (autoregressive model) was adjusted to remove any type of autocorrelation, opting for an AR (4) model, that is, with 4 lags of the dependent variable. The regression adjusted with the AR (4) model is as follows (equation 4): where $d C C I_{j}$ is the first temporary difference of the Consumer confidence index; $l(1 / 4) C C I_{j}$ are the 4 lags of the Consumer confidence index; $d C P I_{j}$ is the first temporary difference of the Consumer price index; $d I N D P R O D_{j}$ is the first temporary difference of the Industrial production index; $d S T I N T_{j}$ is the first temporary difference of the Short term interest rate; $d t$ is the dummy variable.

$$
d C C I_{j}=l(1 / 4) C C I_{j}+d C P I_{j}+d I N D P R O D_{j}+d S T I N T_{j}+d t
$$

The application of the lags helped to eliminate the existing autocorrelation, since the values of the test statistic by Durbin Watson (Durbin and Watson, 1950) are close to 2, thus not rejecting the null hypothesis of non-existence of autocorrelation. According to the Breusch-Godfrey LM autocorrelation test (Breusch, 1978 and Godfrey, 1978) the null hypothesis is also not rejected, therefore there is no autocorrelation.

After all the assumptions to perform the regression were achieved, it was possible to obtain the investor sentiment orthogonalized by the macroeconomic variables and proceed to the estimation of the ARCH family model to study the influence of investor sentiment on the volatility of the PSI 20 and the IBEX 35.

Before proceeding with the estimation of the TGARCH model, it is necessary to check whether the stationarity assumptions in the mean equation are met, the lack of autocorrelation and in this specific case, the presence of heteroscedasticity because we are facing auto-regressive and heteroscedastic models. In the next tables the accomplishment of the assumptions for the Portuguese and Spanish market are shown.

Table 2. Assumptions for the Portuguese market

\begin{tabular}{|c|c|c|c|c|c|c|}
\hline \multirow[t]{5}{*}{ Stationarity } & \multicolumn{2}{|c|}{$\begin{array}{l}\text { Augmented Dickey } \\
\text { Fuller (ADF) test }\end{array}$} & \multirow{2}{*}{$\begin{array}{c}\text { Durbin } \\
\text { Watson test } \\
\text { Test estatistic }\end{array}$} & \multirow{2}{*}{$\begin{array}{c}\text { Breusch-Godfrey } \\
\text { LM test } \\
\text { P-value }\end{array}$} & \multicolumn{2}{|c|}{ White test } \\
\hline & Variables & P-value & & & $\begin{array}{c}\text { Test } \\
\text { estatistic }\end{array}$ & P-value \\
\hline & logreturn & 0.0000 & & & & \\
\hline & 1.logreturn & 0.0000 & & & & \\
\hline & 1.sen & 0.0000 & & & & \\
\hline \multicolumn{3}{|c|}{ Autocorrelation } & 1.993107 & 0.8801 & & \\
\hline \multicolumn{3}{|c|}{ Heteroscedasticity } & & & 11.26 & 0.0465 \\
\hline
\end{tabular}

Table 3. Assumptions for the Spanish market

\begin{tabular}{|c|c|c|c|c|c|c|}
\hline \multirow[t]{5}{*}{ Stationarity } & \multicolumn{2}{|c|}{$\begin{array}{l}\text { Augmented Dickey } \\
\text { Fuller (ADF) test }\end{array}$} & \multirow{2}{*}{$\begin{array}{c}\text { Durbin } \\
\text { Watson test } \\
\text { Test estatistic }\end{array}$} & \multirow{2}{*}{$\begin{array}{c}\text { Breusch-Godfrey } \\
\text { LM test } \\
\text { P-value }\end{array}$} & \multicolumn{2}{|c|}{ White test } \\
\hline & Variables & P-value & & & $\begin{array}{c}\text { Test } \\
\text { estatistic }\end{array}$ & P-value \\
\hline & logreturn_esp & 0.0000 & & & & \\
\hline & 1.logreturn_esp & 0.0000 & & & & \\
\hline & 1.sent & 0.0000 & & & & \\
\hline \multicolumn{2}{|c|}{ Autocorrelation } & & 1.952082 & 0.2871 & & \\
\hline \multicolumn{2}{|c|}{ Heteroscedasticity } & & & & 16.15 & 0.0064 \\
\hline
\end{tabular}

Once validated the assumptions, it was necessary estimating the TGARCH model, to test whether the time series under study includes the presence of ARCH effects, that is, to verify whether the time series has volatility clustering. 
For this purpose, the ARCH-LM test was performed (Engle, 1982) showing that there are ARCH effects, which allows us to execute the TGARCH model.

Table 4. Arch effects assumptions for the Portuguese and Spanish market

\begin{tabular}{lrc}
\hline ARCH-LM test & Test estatistic & P-value \\
\hline Portugal & 14.662 & 0.0021 \\
\hline Spain & 13.182 & 0.0402 \\
\hline
\end{tabular}

In order to analyse the impact of investor sentiment on market volatility and capture the asymmetric effect of the impact of good and bad news, the TGARCH model was applied, obtaining the following results.

Table 5. TGARCH Model for Portugal and Spain

\begin{tabular}{|c|c|c|c|c|c|c|}
\hline logreturn & Coef. & Std.Err. & $\mathrm{z}$ & $\mathrm{P}>|\mathrm{z}|$ & \multicolumn{2}{|c|}{ [95\% Confid. Interv.] } \\
\hline \multicolumn{7}{|l|}{ Portugal: } \\
\hline \multicolumn{7}{|l|}{ logreturn } \\
\hline 1.logreturn & 0.3844076 & 0.5156812 & 0.75 & 0.456 & -0.6263089 & 1.395124 \\
\hline 1.sen & 0.0566481 & 0.0382462 & 1.48 & 0.139 & -0.0183131 & 0.1316093 \\
\hline cons & 0.0036165 & 0.0039077 & 0.93 & 0.355 & -0.0040424 & 0.0112755 \\
\hline \multicolumn{7}{|l|}{ HET } \\
\hline $\operatorname{sen}(\vartheta)$ & -9.250741 & 4.736036 & -1.95 & 0.051 & -18.5332 & 0.0317196 \\
\hline $\operatorname{cons}(\mu)$ & -8.861193 & 0.5651157 & -15.68 & 0.000 & -9.968799 & -7.753587 \\
\hline \multicolumn{7}{|l|}{$\mathrm{ARCH}$} \\
\hline $\operatorname{arch}(\alpha)$ & 0.1721096 & 0.0602954 & 2.85 & 0.004 & 0.0539327 & 0.2902865 \\
\hline $\operatorname{tarch}(\gamma)$ & -0.062802 & 0.0741645 & -0.85 & 0.397 & -0.2081617 & 0.0825578 \\
\hline $\operatorname{garch}(\beta)$ & 0.7784334 & 0.0726824 & 10.71 & 0.000 & 0.6359785 & 0.9208883 \\
\hline logreturn & Coef. & Std.Err. & $\mathrm{z}$ & $\mathrm{P}>|\mathrm{z}|$ & [95\% Confic & Interv.] \\
\hline \multicolumn{7}{|l|}{ Spain: } \\
\hline \multicolumn{7}{|l|}{ logreturn } \\
\hline 1.logreturn & 0.2310829 & 0.1936875 & 1.19 & 0.233 & -0.1485376 & 0.6107034 \\
\hline 1.sent & 0.1188392 & 0.037231 & 3.19 & 0.001 & 0.0458679 & 0.1918105 \\
\hline cons & 0.0035615 & 0.0027001 & 1.32 & 0.187 & -0.0017305 & 0.0088536 \\
\hline \multicolumn{7}{|l|}{$\begin{array}{l}\text { HET } \\
\text {. }\end{array}$} \\
\hline $\operatorname{sent}(\vartheta)$ & -9.344329 & 2.817595 & -3.32 & 0.001 & -14.86671 & -3.821945 \\
\hline $\operatorname{cons}(\mu)$ & -7.858267 & 0.439818 & -17.87 & 0.000 & -8.720294 & -6.99624 \\
\hline \multicolumn{7}{|l|}{$\mathrm{ARCH}$} \\
\hline $\operatorname{arch}(\alpha)$ & 0.2063002 & 0.0687996 & 3.00 & 0.003 & 0.0714555 & 0.3411449 \\
\hline $\operatorname{tarch}(\gamma)$ & -0.1842943 & 0.0756293 & -2.44 & 0.015 & -0.332525 & -0.0360637 \\
\hline $\operatorname{garch}(\beta)$ & 0.6609599 & 0.1006894 & 6.56 & 0.000 & 0.4636123 & 0.8583074 \\
\hline
\end{tabular}

Empirical data support that there is no asymmetric effect of good and bad news on the PSI 20 volatility since the $\gamma$ coefficient is not statistically significant, but the asymmetric effect of good and bad news is shown in the IBEX 35 since the $\gamma$ coefficient is statistically significant and has a negative value, we can say that there is evidence that the 
impact of news is asymmetric once that $\gamma \neq 0$, concluding that the impact of positive news on volatility is greater than negative news of the same magnitude, confirming the existence of a leverage effect. According to Fernandes (2013), the percentage of individual investors in Portugal is inferior to the Spanish market, what would explain why there is no asymmetric effect of good and bad news on the PSI 20 volatility, since that the individual investors are more prone to the influence of irrational factors than of the rational ones. Furthermore, Portuguese stock market has small liquidity and a small dimension (around 50 billion market cap). Accordingly, it is not strange that sentiment measured by the Consumer sentiment proxy indicator barely influence PSI20 volatility and there is no TARCH effect of good or bad news on volatility. The results also corroborate the study by Lee et al. (2002), who states that the asymmetry coefficient is negative since positive shocks cause a downward trend in volatility. The same conclusion was obtained by Sudha (2014) who states that since the coefficient of negative asymmetry, the intensity of volatility tends to have a downward rather than an upward trend. One explanation for why the value of the asymmetry coefficient is negative rather than positive according to Aydogan's (2016) results may be due to the fact that the temporal amplitude of our study is much larger and the database includes more information.

The sum of the ARCH and GARCH coefficients is 0.950543 for the Portuguese market and 0.8672601 for the Spanish market, which is very close to one, and is an indicator that the volatility shocks are persistent in both the short and long term, in line with the results obtained by Aydogan (2016). The $\beta$ coefficient is positive and statistically significant, which shows that there is a strong GARCH effect in the markets, indicating a long memory in the variance, which means that after a shock the volatility remains for a considerable period. The investor sentiment coefficient, $\vartheta$, is statistically significant and has a negative value, which highlights the greater persistence of negative shocks in the conditioned variance (the lower the sentiment, higher the volatility of the PSI20 and IBEX 35 return) corroborating Aydogan's (2016) study in which the German and French markets also show negative and statistically significant values concluding that they are more sensitive to the negative shocks of investor sentiment. The influence of the investor sentiment can be explained by the collectivistic culture evidenced by Hofstede (2001), and according to Schmelling (2009) stock markets in collectivistic countries are more heavily influenced by investor sentiment. Portugal and Spain are largely dominated by institutional investors and according to Aydogan (2016) institutional investors, pessimism among investors will generally cause stock market volatility to rise and eventually, the impact of institutional investors sentiment on stock market volatility will have a substantial economic effect.

The ARCH effect is also felt through the short-term impact of shocks that occurred in the markets in the previous period on current volatility. An increase in consumer sentiment is associated with a decrease in volatility. The results support the behavioural theory of finance, which suggests that volatile markets are more prone to changes in investor sentiment.

Regarding the mean equation, we found that lagged sentiment does not influence Portuguese stock market returns but, on the opposite, has a positive relation with returns forecast on Spanish markets. Higher sentiment leads to lower volatility and higher returns. Similar results even with different proxy measures were achieved by Sayim \& Rahman (2015) who show that a positive investor sentiment tends to increase Turkish stocks returns, and that optimism produce positive expectations, tumbling uncertainty, and reducing the volatility of stock returns. Also, Anusakumar et al. (2017) conclude that there is a positive relationship between market sentiment and returns however the relationship does not verify at the country level. Frugier (2016) defends that portfolios composed of shares of large European companies, present a link between investor sentiment, stock volatility and future returns. Da et al. (2015) used an internet text sentiment and find that it predicted short-term return reversals and increases in volatility. Labidi \& Yaakoubi (2016) argue that exposure to aggregate volatility risk is negatively associated to returns when sentiment is low. This connection loses its significance when sentiment is high. Kumari and Mahakud (2015) show that higher market excess returns are positively associated with the lower conditional volatility that results from bullish alterations in investor sentiment for the market as the opposite also verifies.

But other authors found a negative relation of sentiment with future returns. Among them Baker and Wurgler (2006) discovered that when sentiment is low, following returns are higher on newly listed stocks than older stocks and also in high return volatility than low-return volatility stocks, as in nonprofit stocks than profitable ones, and in dividend nonpayers than dividend payers. When sentiment is high, those patterns change. Smales (2017) defend that firms that are more subjective to value, difficult to arbitrage react more to changes in investor sentiment. The author also concludes that lower sentiment produces a greater influence on market returns during a recession for speculative shares.

Asymmetric results are also found as in the works of Lutz (2016) who defends that the effects of sentiment are asymmetric stating that during investor sentiment contractions, high sentiment predicts low future returns for the 
cross-section stocks return and for the market, overall. The relation between sentiment and future returns is positive in the case of sentiment expansions.

Regarding the results of the study carried out by Aydogan (2016), whose research encouraged this work to be carried out, our study has a broader scope, 31 years (in monthly data) from January 1988 to May 2019 compared to the study of Aydogan (2016) 11 years, from January 2004 to June 2015, and covers the Spanish and Portuguese markets. As our analysis covers a longer period, it makes our conclusions more solid because it includes more information.

The difference observed in the signs of the asymmetry coefficient values verified in this study in relation to the work developed by Aydogan (2016) can be explained by the database used in this study to include data even after the Black Monday crisis that occurred on October 19, 1987 and, therefore, have data that reflect the improvement of stability in international markets.

A policy implication of these results is that key market players could use communication strategically and get the media to report their confidence to increase investor sentiment and, therefore, avoid feeding negative thoughts about the state of the economy. Despite the previous idea the fact is that the investor's feeling, or his pessimism or optimism conditions the growth and development of capital market activities. At same time, investors can improve the performance of their portfolio, considering investor sentiment as an important determinant of stock market volatility in asset pricing models. The results can also contribute to formulating policies that allow investors to stabilize their feelings, reducing the volatility and uncertainty of the stock market.

\section{Conclusion}

The aim of this study was to investigate the impact that investor sentiment has on the volatility of PSI 20 and IBEX 35, based on the methodology used by Aydogan (2016). Consumer Confidence Index data attempted to capture the effect that investor sentiment would have on conditioned volatility. As respect to the asymmetric effect of good and bad news the results show that in the case of the Portuguese market the asymmetric effect couldn't be detected, but for the Spanish market the asymmetric effect was shown concluding that the impact of positive news on volatility is greater than negative news of the same magnitude, also confirming the presence of a leverage effect. Regarding the investor sentiment, the conclusions are that the Portuguese and Spanish market are more sensitive to the negative shocks of investor sentiment, showing that a lower investor sentiment provides a higher volatility.

The so-called ARCH effects are the short-term impact of shocks on market volatility in the previous period that are transmitted in current volatility, showing that Portugal and Spain have ARCH effects. In comparison to the study by Aydogan (2016) France, Germany, Italy, Ireland, Spain and Greece also have ARCH effect.

The results of this study can be used by investors and policymakers. The investors could improve their results by considering the investor sentiment as an important factor to take into consideration when making market investment choices. The policymakers could with the effect of the investor sentiment on the volatility, gain new perspectives and so try to stabilize future volatility shocks.

One of the main limitations of the study stems from considering only the Portuguese and Spanish markets in comparative terms, despite the high time horizon contemplated.

Future work should frame other non-OECD countries by broadening the benchmark, using another alternative indicator to measure consumer sentiment beyond the Consumer Confidence Index, and using other macroeconomic variables to calculate sentiment.

\section{Acknowledgements}

This work is funded by National Funds through the FCT - Foundation for Science and Technology, I.P., within the scope of the project $\operatorname{Ref}^{\mathrm{a}} \mathrm{UIDB} / 05583 / 2020$. Furthermore we would like to thank the Research Centre in Digital Services (CISeD) and the Polytechnic of Viseu for their support.

\section{References}

Anusakumar, S. V., Ali, R., \& Wooi, H. C. (2017). The effect of investor sentiment on stock returns: insight from emerging Asian markets. Asian Academy of Management Journal of Accounting \& Finance, 13(1).

Aydogan, B. (2016). Sentiment dynamics and volatility of international stock markets. Eurasian Business Review, 1-13.

Baker, M., \& Wurgler, J. (2006). Investor sentiment and the cross - section of stock returns. The Journal of Finance, 61(4), 1645-1680. 
Baker, M., \& Wurgler, J. (2007). Investor Sentiment in the Stock Market. Journal of Economic Perspectives, 21(2), $129-151$.

Baker, M., Wurgler, J., \& Yuan, Y. (2012). Global, local, and contagious investor sentiment. Journal of Financial Economics, 104(2), 272-287.

Barberis, N., \& Thaler, R. (2002). A Survey of Behavioral Finance. NBER Working Paper No. 9222.

Barberis, N., Shleifer, A., \& Wurgler, J. (2005). Comovement. Journal of Financial Economics, 75(2), 283-317.

Bentes, S. (2011). Sobre a Medição da Volatilidade nos Mercados Bolsistas Internacionais: Evidência dos Países do G7. Lisboa: Edições Colibri/Instituto Politécnico de Lisboa.

Bhimjee, D. C., Ramos, S. B., \& Dias, J. G. (2016). Banking industry performance in the wake of the global financial crisis. International Review of Financial Analysis, 48, 376-387.

Bollerslev, T. (1986). Generalized autoregressive conditional heteroskedasticity. Journal of Econometrics, 31, 307-327.

Bollerslev, T., \& Ole Mikkelsen, H. (1996). Modeling and pricing long-memory in stock market volatility. Journal of Econometrics, 73, 151-184.

Bowerman, B. L. \& O’Connel, R. T. (1979). Time series and forecasting. California, Duxbury Press.

Breusch, T. S. (1978). Testing for autocorrelation in dynamic linear models. Australian Economic Papers, 17(31), $334-355$.

Breusch, T. S., \& Pagan, A. R. (1979). A Simple Test for Heteroscedasticity and Random Coefficient Variation. Econometrica, 47(5), 1287-1294.

Brown, G. W., \& Cliff, M. T. (2004). Investor sentiment and the near-term stock market. Journal of Empirical Finance, 11(1), 1-27.

Brown, G. W., \& Cliff, M. T. (2005). Investor Sentiment and Asset Valuation. The Journal of Business, 78(2), 405-440.

Campbell, J. Y., Lo, A.W., \& MacKinlay, A.C. (1997). The econometrics of financial markets. Princeton, NJ: Princeton University press.

Chang, Y. Y., Faff, R., \& Hwang, C.-Y. (2012). Local and global sentiment effects, and the role of legal, trading and information environments.

Charoenrook, A. (2006). Does sentiment matter?. Working paper, Vanderbilt University.

Chen, N., Roll, R., \& Ross, S. A. (1986). Economic Forces and the Stock Market. The Journal of Business, 59(3), 383-403.

Chui, A., Titman, S., \& Wei, J. (2010). Individualism and Momentum around the World. The Journal of Finance, 65(1), 361-92. https://doi.org/10.1111/j.1540-6261.2009.01532.x

Corredor, P., Ferrer, E., \& Santamaria, R. (2013). Investor sentiment effect in stock markets: Stock characteristics or country-specific factors?. International Review of Economics and Finance, 27, 572-591.

Corredor, P., Ferrer, E., \& Santamaria, R. (2015). The impact of investor sentiment on stock returns in emerging markets: The case of Central European Markets. Eastern European Economics, 53, 328-355.

Da, Z., Engelberg, J., \& Gao, P. (2015). The sum of all FEARS investor sentiment and asset prices. Review of Financial Studies, 28(1), 1-32. https://doi.org/10.1093/rfs/hhu072

De Bondt, W., Muradoglu, G., Shefrin, H., \& Staikouras, S. K., (2008). Behavioral finance: Quo vadis?. Journal of Applied Finance, 18(2), 7-18.

De Long, J. B., Shleifer, A., Summers, L. H., \& Waldmann, R. J. (1990). Noise Trader Risk in Financial Markets. Journal of Political Economy, 98(4), 703-738.

Dergiades, T. (2012). Do investors' sentiment dynamics affect stock returns? Evidence from the US economy. Economics Letters, 116(3), 404-407.

Dickey, D. A., \& Fuller, W. A. (1979). Distribution of the estimators for eutoregressive time series with a unit root. Journal of the American Statistical Association, 74(366), 427-431.

Dungey, M. (2009). The tsunami: measures of contagion in the 2007-08 credit crunch. Cesifo Forum, 9(4), 33-34. 
Durbin, J., \& Watson, G. S. (1950). Testing for Serial Correlation in Least Squares Regression: I. Biometrika, $37(3 / 4), 409-428$.

Efron, B. (1979). Computers and the theory of statistics: thinking the unthinkable. SIAM Review, 21(4), 460-480.

Engle, R.F. (1982). Autoregressive conditional heteroskedasticity with estimates of the variance of United Kingdom inflation. Econometrica, 50(4), 987-1007.

Fama, E. F. (1965). The Behavior of Stock-Market Prices. The Journal of Business, 38(1), 34-105.

Fama, E. F. (1970). Efficient Capital Markets: A Review of Theory and Empirical Work. The Journal of Finance, 25(2), 383-417.

Fama, E.F., \& Schwert, G.W., (1977). Asset returns and inflation. Journal of Financial Economics, 5, 115-146.

Feldman, T. (2010). A More Predictive Index of Market Sentiment. Journal of Behavioral Finance, 11(4), 211-223.

Fernandes, C. M. D. A., Gonçalves, P. M. M. G., \& Vieira, E. F. S. (2013). Does sentiment matter for stock market returns? Evidence from a small European market. Journal of Behavioral Finance, 14(4), 253-267.

Ferreira, Domingos. (2009). Opções Financeiras - Gestão de Risco, Especulação e Arbitragem (2nd ed.). Lisboa: Edições Sílabo.

Finter, P., Niessen-Ruenzi, A., \& Ruenzi, S. (2012). The impact of investor sentiment on the German stock market. Journal of Business Economics, 82(2), 132-163.

Fisher, K. L., \& Statman, M. (2000). Investor Sentiment and Stock Returns. Financial Analysts Journal, 56(2), 16-23.

Fisher, K. L., \& Statman, M. (2003). Consumer Confidence and Stock Returns. The Journal of Portfolio Management, 30(1), 115-127.

Frugier, A. (2016). Returns, volatility and investor sentiment: Evidence from European stock markets. Research in International Business and Finance, 38, 45-55.

Glosten, L.R., Jagannathan, R., \& Runkle, D.E. (1993). On the relation between value and volatility of nominal excess returns on stock. Journal of Finance, 48(5), 1179-1801.

Glushkov, D. (2006). Sentiment Beta. SSRN Electronic Journal.

Godfrey, L. G. (1978). Testing Against General Autoregressive and Moving Average Error Models when the Regressors Include Lagged Dependent Variables. Econometrica, 46(6), 1293-1301.

Han, B. (2007). Investor Sentiment and Option Prices. Review of Financial Studies, 21(1), 387-414.

He, G., Zhu, S., \& Gu, H. (2017). On the Construction of Chinese Stock Market Investor Sentiment Index. Cogent Economics \& Finance, 5(1), 1412230.

Hofstede, G. (2001). Culture's Consequences: Comparing Values, Behaviors, Institutions, and Organizations across Nations. Administrative Science Quarterly, 48(1), 127-131.

Horta, P., \& Lobão, J. (2018). Global and Extreme Dependence Between Investor Sentiment and Stock Returns in European Markets. Journal of Behavioral Finance, 19(2), 141-158.

Hughen, J. C., \& McDonald, C. G. (2005). WHO ARE THE NOISE TRADERS?. Journal of Financial Research, 28(2), 281-298.

Kendall, M. G., \& Hill, A. B. (1953). The Analysis of Economic Time-Series-Part I: Prices. Journal of the Royal Statistical Society, Series A (General), 116(1), 11.

Khan, M., \& Ahmad, E. (2018). Measurement of Investor Sentiment and Its Bi-Directional Contemporaneous and Lead-Lag Relationship with Returns: Evidence from Pakistan. Sustainability, 11(1), 94.

Kumar, A., \& Lee, C. M. C. (2006). Retail Investor Sentiment and Return Comovements. The Journal of Finance, 61(5), 2451-2486.

Kumari, J., \& Mahakud, J. (2015). Does investor sentiment predict the asset volatility? Evidence from emerging stock market India. Journal of Behavioral and Experimental Finance, 8, 25-39.

Labidi, C., \& Yaakoubi, S. (2016). Investor sentiment and aggregate volatility pricing. The Quarterly Review of Economics and Finance, 61, 53-63. 
Lee, C. M. C., Shleifer, A., \& Thaler, R. H. (1991). Investor Sentiment and the Closed-End Fund Puzzle. The Journal of Finance, 46(1), 75-109.

Lee, W.Y., Jiang, C.X., \& Indro, D.C. (2002). Stock market volatility, excess returns, and the role of investor sentimento. Journal of Banking \& Finance, 26, 2277-2299.

Lemmon, M., \& Portniaguina, E. (2006). Consumer confidence and asset prices: Some empirical evidence. Review of Financial Studies, 19(4), 1499-1529.

Lutz, C. (2016). The asymmetric effects of investor sentiment. Macroeconomic Dynamics, 20(6), 1477-1503.

Lux, T. (2011). Sentiment dynamics and stock returns: the case of the German stock market. Empirical Economics, 41(3), 663-679.

Mandelbrot, B. (1963). The Variation of Certain Speculative Prices. The Journal of Business, 36(4), 394-419.

Nelsen, Roger B. (1999). An Introduction to Copulas. Springer-Verlag New York, Inc.

Nofsinger, J. R. (2005). Social Mood and Financial Economics. Journal of Behavioral Finance, 6(3), 144-160.

OECD (1961). Organisation for Economic Co-operation and Development. Retrieved July 26, 2019, from https://data.oecd.org/

Qiu, L., \& Welch, I. (2006). Investment sentiment measures. Working Paper.

Reis, P. M. N., \& Pinho, C. (2020a). A Reappraisal of the Causal Relationship between Sentiment Proxies and Stock Returns. Journal of Behavioral Finance, 1-23.

Reis, P. M. N., \& Pinho, C. (2020b). A new European investor sentiment index (EURsent) and its return and volatility predictability. Journal of Behavioral and Experimental Finance, 100373.

Ridberg, T. H. (2000). Realistic Statistical Modelling of Financial Data. International Statistical Review, 68, 233-258.

Ritter, J., (2003). Investment banking and securities issuance. In Harris, M., \& Stulz, R., R. (Eds.), Handbook of the Economics of Finance (Chapter 5). Constantinites, North-Holland, Amsterdam.

Sayim, M., \& Rahman, H. (2015). The relationship between individual investor sentiment, stock return and volatility: Evidence from the Turkish market. International Journal of Emerging Markets, 10(3), 504-520.

Sayim, M., Morris, P., \& Rahman, H. (2013). The effect of US individual investor sentiment on industry-specific stock returns and volatility. Review of Behavioral Finance 5(1), 58-76.

Schmeling, M. (2009), Investor sentiment and stock returns: some international evidence. Journal of Empirical Finance, 16, 394-408.

Schneller, D., Heiden, S., Heiden, M., \& Hamid, A. (2017). Home is Where You Know Your Volatility - Local Investor Sentiment and Stock Market Volatility. German Economic Review, 19(2), 209-236.

Silva, W. S., Sáfadi, T., \& Castro Júnior, L. G. (2005). Uma análise empírica da volatilidade do retorno de commodities agrícolas utilizando modelos ARCH: os casos do café e da soja. Revista de Economia e Sociologia Rural, 43(1), 119-134.

Simões, V. E. (2011). Investor Sentiment and the Market Reaction to Dividend News: European Evidence. Managerial Finance, 37(12), 1213-45.

Smales, L. A. (2017). The importance of fear: investor sentiment and stock market returns. Applied Economics, 49(34), 3395-3421.

Smidt, S. (1968). A New Look at the Random Walk Hypothesis. The Journal of Financial and Quantitative Analysis, 3(3), 235-261.

Solt, M. E., \& Statman, M. (1988). How Useful is the Sentiment Index?. Financial Analysts Journal, 44(5), 45-55.

Spyrou, S. (2013). Investor Sentiment and Yield Spread Determinants: Evidence from European Markets. Journal of Economic Studies, 40(6), 739-62. https://doi.org/10.1108/JES-01- 2012-0008

Statman, M. (2014). Behavioral finance: Finance with normal people. Borsa Istanbul Review, 14(2), 65-73.

Sudha, S. (2014). Risk-return and Volatility analysis of Sustainability Index in India. Environment. Development and Sustainability, 17(6), 1329-1342. 
Taylor, S. J. (1994). Modelling Financial Time Series. Chichester: John Wiley \& Sons.

Tsuji, C. (2006). Does investors' sentiment predict stock price changes? With analyses of naive extrapolation and the salience hypothesis in Japan. Applied Financial Economics Letters, 2(6), 353-359.

Verma, R., \& Soydemir, G. (2006). The Impact of U.S. Individual and Institutional Investor Sentiment on Foreign Stock Markets. Journal of Behavioral Finance, 7(3), 128-144.

Wang, Y., Li, C., \& Lin, C. (2009). The impact of investor sentiment on the futures market, evidence from the Taiwan futures exchange. International Research Journal of Finance and Economics, 28, 134-151.

Wang, Y.-H., Keswani, A., \& Taylor, S. J. (2006). The relationships between sentiment, returns and volatility. International Journal of Forecasting, 22(1), 109-123.

White, H. (1980). A Heteroskedasticity-Consistent Covariance Matrix Estimator and a Direct Test for Heteroskedasticity. Econometrica, 48(4), 817-838.

Yu, J., Huang, H.-H., \& Hsu, S.-W. (2014). Investor Sentiment Influence on the Risk-Reward Relation in the Taiwan Stock Market. Emerging Markets Finance and Trade, 50, 174-188.

Zakoian, J.-M. (1994). Threshold heteroskedastic models. Journal of Economic Dynamics and Control, 18(5), 931-955.

Zouaoui, M., Nouyrigat, G., \& Beer, F. (2011). How Does Investor Sentiment Affect Stock Market Crises? Evidence from Panel Data. The Financial Review, 46, 723-747.

Zweig, M. E. (1973). An Investor Expectations Stock Price Predictive Model Using Closed-End Fund Premiums. The Journal of Finance, 28(1), 67-78.

\section{Copyrights}

Copyright for this article is retained by the author(s), with first publication rights granted to the journal.

This is an open-access article distributed under the terms and conditions of the Creative Commons Attribution license (http://creativecommons.org/licenses/by/4.0/). 